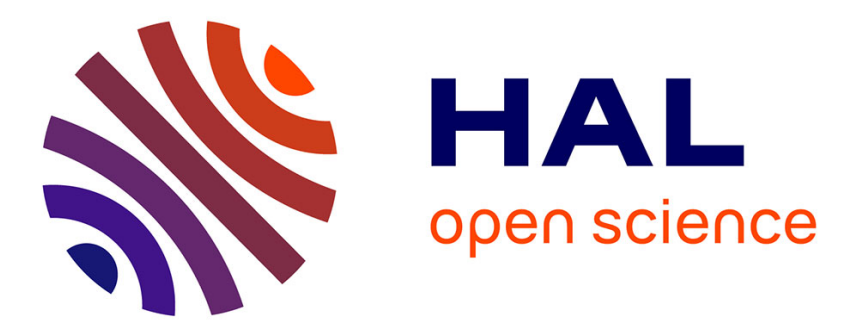

\title{
Fretting Wear of Coated Surfaces Under Gross Slip Conditions
}

\author{
Hana Jerbi, Daniel Nélias, Marie-Christine Baietto
}

\section{To cite this version:}

Hana Jerbi, Daniel Nélias, Marie-Christine Baietto. Fretting Wear of Coated Surfaces Under Gross Slip Conditions. ASME 2014 12th Biennial Conference on Engineering Systems Design and Analysis, Jul 2014, Copenhagen, Denmark. 10.1115/ESDA2014-20264 . hal-01951566

\section{HAL Id: hal-01951566 https://hal.science/hal-01951566}

Submitted on 7 Jul 2021

HAL is a multi-disciplinary open access archive for the deposit and dissemination of scientific research documents, whether they are published or not. The documents may come from teaching and research institutions in France or abroad, or from public or private research centers.
L'archive ouverte pluridisciplinaire HAL, est destinée au dépôt et à la diffusion de documents scientifiques de niveau recherche, publiés ou non, émanant des établissements d'enseignement et de recherche français ou étrangers, des laboratoires publics ou privés. 


\section{FRETTING WEAR OF COATED SURFACES UNDER GROSS SLIP CONDITIONS}

\author{
H. Jerbi \\ LaMCoS \\ INSA-Lyon \\ CNRS UMR5259 \\ Villeurbanne F69621, France
}

\author{
D. Nelias* \\ LaMCoS \\ INSA-Lyon \\ CNRS UMR5259 \\ Villeurbanne F69621, France \\ daniel.nelias@insa-lyon.fr
}

\author{
M-C. Baietto \\ LaMCoS \\ INSA-Lyon \\ CNRS UMR5259 \\ Villeurbanne F69621, France \\ marie-christine.baietto@insa-lyon.fr
}

\section{ABSTRACT}

Blade-disk contact within high pressure compressor, is a high temperature fretting contact zone submitted to high stress levels. Therefore, it is important to estimate the various damages encountered in this area in order to correctly predict the lifetime of the parts. Coatings are used in order to improve the strength of the parts. In the framework of Innolub project, this study aims at developing a numerical model of coated contact accounting for wear and temperature. The objective is to estimate the kinetics of wear, to simulate worn surfaces and to allow the manufacturer to produce analyses of design with worn surfaces using a fast, efficient and reliable method of calculation.

Keyword: Coating, High temperatures, Fretting, Wear, Energy approach, Gross slip

\section{INTRODUCTION}

The aerospace is a sector of activities where many challenging problems arise. The area of contact between the blade and disk in turbo-machinery has been identified as a critical area for the nucleation of damage for the safety of the flying machine. To control damage, coatings are applied. There is a great need for innovative coatings given good lubricating properties under high temperatures conditions and limited wear of the parts. The prediction of wear is a challenging task. Many formalizations have been proposed for quantitative approach to wear. More than 300 have been identified by Meng and Ludema [1], resting on different applications [2-5]. The energy theory of wear, inspired by the Archard's theory, is selected as it is very simple to implement. This work aims at developing a numerical model of coated contact accounting for wear and temperature. The objective is to perform wear prediction using semi analytical computational methods. This research is based on previous works [6-8] developed at LaMCoS. Gallego et al. [9] proposed an elastic contact model under stick-slip conditions. This model has been extended to the phenomenon of fretting wear [10] and under partial slip conditions [11]. Analytical solutions to take into account the plasticity in the resolution of the tangential contact have been developed [12]. The presence of heterogeneities within the contacting bodies has been later introduced and the model applied to the elastic-plastic contact under fretting wear conditions [13]. Finally, Leroux [14] extended the formulation and proposed a model to account for the presence of multiple spherical inclusions based on the equivalent inclusion method originally proposed by Eshelby. The first part of this paper focuses on coating. The coating is modeled as a cluster of inclusions based on the Eshelby's theory. Validation is obtained by comparison with multigrid results. In the second part, wear simulation is carried out illustrating the model robustness and efficiency. Results are then presented and briefly discussed.

* corresponding author. 


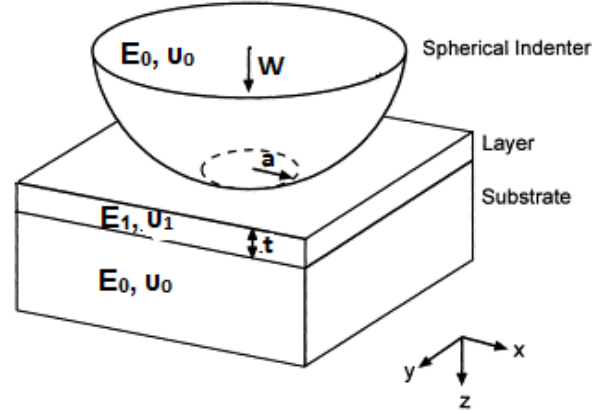

Figure 1: 3D model of sphere/coated plane elastic contact.

\section{Coating: Modeling and Validation \\ 1.1 Modeling}

A rigid indenter is considered, with a spherical tip of radius $\mathrm{R}$. It is pressed against an elastic flat of properties $\left(E_{2}=210 \mathrm{GPa}\right.$, $\left.v_{2}=0.3\right)$ covered by a layer $\left(E_{1}, v_{1}\right)$ - more or less rigid than the substrate - and of thickness 't', see Fig. 1. 'W' is the normal load and ' $a$ ' the contact radius. The equivalent inclusion method in the sense of Eshelby allows to describe accurately the effect of inhomogeneities. This method is modified and improved in order to take into account the mutual influence between neighboring heterogeneous inclusions. A few analytical solutions have been obtained for inclusions of simple geometry embedded in an infinite isotropic medium, such as ellipsoidal [15], cuboidal [16] and cylindrical $[17,18]$ inclusions. The aim of this part is to model an isotropic heterogeneous coated contact, based on [14, 19], using an arrangement of cuboidal inclusions to describe the layer. The Eshelby's equivalent inclusion method is considered to quantify the surrounding material stresses. An iterative process is implemented to determine the displacements and stress fields caused by the eigenstrains of all inclusions, accounting for interactions between close inclusions. The proposed method can be seen as an enrichment technique for which the effect of heterogeneous inclusions is superimposed on the homogeneous solution. 3D and 2D Fast Fourier Transforms are utilized to improve the computational efficiency. Displacements and pressure relationships account for this contribution. For more details on the method and algorithm the reader may refer to [14].

\subsection{Validation}

The contact solution and internal stress field obtained for the $3 \mathrm{D}$ coated model are compared with results obtained using a 3D multigrid solver [20]. A sphere is pressed against a coated half space. The coating elastic constants are: $E_{1}=420 G P a=2 * E_{2}$, $\mathrm{v}_{1}=0.3$ and $\mathrm{t}=0.75 \mu \mathrm{m}=0.25 * \mathrm{a}$. The normal load is kept constant $\mathrm{W}=0.04 \mathrm{~N}$. Figure 2 presents the distribution of pressure obtained using a 3D multigrid solver and the semi-analytical solver.

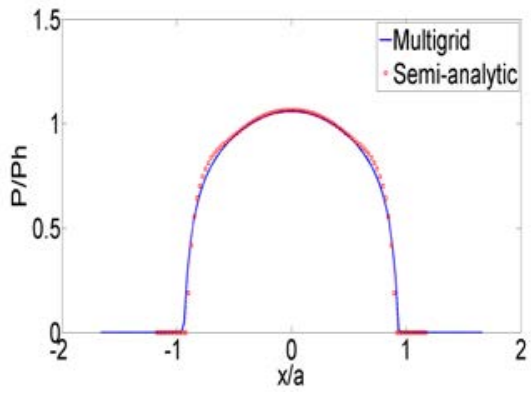

Figure 2: Distribution of pressure: fine mesh $(\mathrm{dx}=0.15 \mu \mathrm{m})$
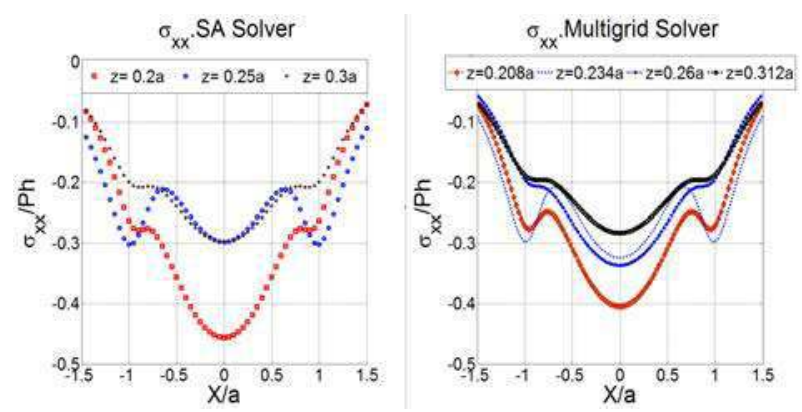

Figure 3: Distribution of stress $\sigma_{x x}$-for a thickness $\mathrm{t}=0.25 \mathrm{a}$ - at different depths $\mathrm{z}$ : fine mesh $(\mathrm{dx}=0.05 \mu \mathrm{m}=0.05 \mathrm{a})$

$\sigma_{x x}$ within the layer and the substrate are plotted in Fig. 3 for a mesh size of $0.15 \mu \mathrm{m}$. The depth at which the stress is calculated is different, which explains the difference here.

\section{Wear: Methodology and simulation \\ 2.1 Methodology}

The tribological analysis of a contact can be understood through the energetic balance. Friction is a dissipated phenomenon, and a part of this frictional dissipated energy is consumed by different processes that conduct to wear [21]. To quantify the wear of a sliding contact, Archard [22] published in 1953 his famous equation: $\mathrm{V}=\alpha_{A R C H A R D} \cdot \mathrm{s} \cdot \frac{P}{K}$.

where $\alpha_{A R C H A R D}$ is the wear coefficient. The worn volume $\mathrm{V}$ is a function of the sliding distance s, the normal applied load $\mathrm{P}$, and the hardness of the softer material $\mathrm{K}$. The friction coefficient does not appear in this equation. However it is often observed that the greater the friction coefficient the larger the wear. In addition, the friction dissipated energy is equal to the work of the tangential load. For these reasons Fouvry and co-workers $[2-4,23,24]$ developed a modified Archard's wear law: $\mathrm{V}=\alpha . \sum_{N} E_{d}$, with $E_{d}$ the frictional dissipated energy density. A method to simulate wear of contacting surfaces is proposed. A wear law based on the energy dissipated by friction, derived from the work of Fouvry, is used. The local sliding amplitude is assumed constant along the 


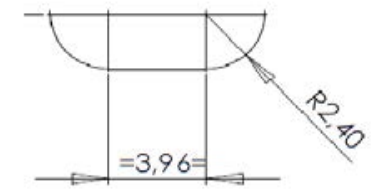

Figure 4: Profile of the punch $[\mathrm{mm}]$ in $(\mathrm{x}, \mathrm{z})$ plane

wear cycles. Wear can concern only one of the contacting bodies, or both. In addition, the worn material is assumed in the numerical procedure to be removed at the end of each cyclic movement only. The input data of the problem are:

$P^{k}, \mathrm{k}=1, . ., \mathrm{N}$ : the normal load history of each cycle

$s^{k}, \mathrm{k}=1, . ., \mathrm{N}$ : the corresponding local sliding amplitude

$\delta_{0}$ : the sliding amplitude

$\Delta \mathrm{N}$ : the number of cycles to update the worn geometry

$N_{\text {max }}$ : the maximum number of cycles

$H_{\text {max }}$ : the maximum value for the wear depth to end the computation

For each cycle, $E_{d}$ is computed at each point. It corresponds to the product of the tangential stress with the sliding distance; thus, in gross slip regime: $E_{d}=\sum_{k=1}^{N} \mu \times p^{k} \times s^{k}$.

The wear depth $\Delta \mathrm{h}$ for one cycle is calculated at each point with an appropriate wear law $\Delta \mathrm{h}=\mathrm{f}\left(E_{d}\right)=\alpha . S . \sum_{N} \delta_{0}(N) E_{d}(N)$. The value is then multiplied by $\Delta \mathrm{N}$, and the geometry is updated before next contact solution and wear calculation. The corresponding wear of each surface is taken into account according to a wear partitioning coefficient WP, equal to 0.5 in the case of an equal wear repartition for each body. The simulation can be stopped through two ways, one when the number of cycles $\mathrm{N}$ exceeds the maximum number of cycles $N_{\max }$, the other when a maximum value of a wear depth is reached. Finally the computation gives the final geometry and the wear distribution.

\subsection{Simulation of a Fretting Wear Test}

The numerical simulations presented here correspond to experimental fretting tests [25]. It consists of fretting tests with a Ti6242 punch/Ti17 plan. The indenter (Ti6242 punch) is considered as a plan with crown radius. The geometry of this punch is shown in Fig. 4. Materials properties are $\left(E_{0}=114 G P a\right.$, $\left.\mathrm{v}_{0}=0.36\right)$ and $\left(E_{2}=110 G P a, v_{2}=0.34\right)$. A slip amplitude $\delta_{0}=100 \mu \mathrm{m}$ is considered. The normal load $\mathrm{W}$ and the friction coefficient $\mu$ are assumed constant all over the cycles and equal to $1150 \mathrm{~N}$ and 0.68 , respectively.

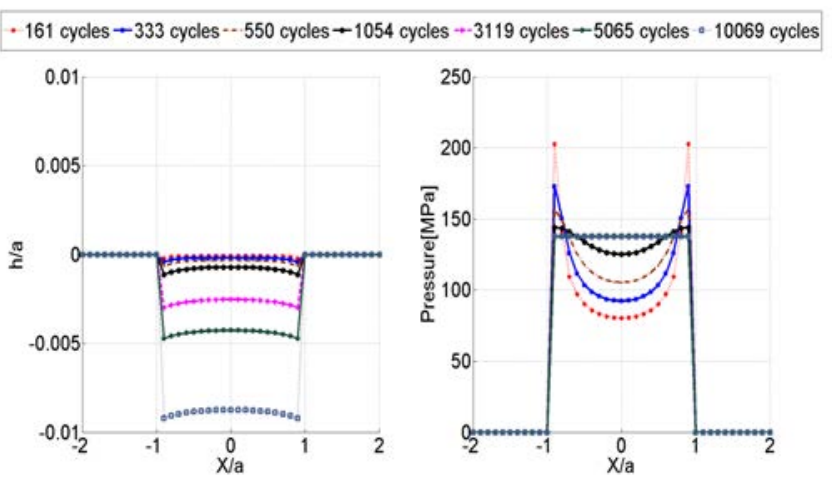

Figure 5: Evolution of wear: pressure and depth

\section{Results and discussions}

For industrial application, the most important element is the lifetime of the disk, which can not be repaired, and whose failure is the most critical. In contrast, the blade root can be repaired, and breaking of the blade can be contained within the engine. Thus, the main objective is to develop a sacrificial deposit which wears out preferentially but which will avoid disk wear (Ti17). Before studying the response of deposit, we aim to characterize wear for uncoated contact to quantify the gain provided by the deposition.

\subsection{Uncoated contact}

A first simulation was carried out to analyze the wear response of uncoated contact $\mathrm{Ti} 6242 \mathrm{~g} / \mathrm{Ti} 17 \mathrm{~g}$. The simulation were conducted by imposing the sliding amplitude $\delta_{0}=100 \mu \mathrm{m}$. The normal load was chosen equal to $1150 \mathrm{~N}$, the friction coefficient to 0.68 and the wear coefficient $\alpha$ to $3 e^{-5} \mathrm{~mm}^{3} / \mathrm{J} .10000$ cycles were realized. Wear is assumed to affect only the plan $(\mathrm{WP}=0)$. The evolution of wear is detailed in the graphs of Fig. 5 in terms of contact pressure history and wear depth history. It can be observed that the pressure distribution has a profile similar to the surface of the punch for the first cycles and after it evolves naturally through a flat profile, i.e., with a uniform increment of wear inside the contact area as the wear law used in our case is proportional to the contact pressure. The area where the wear is maximum is located at the edge of the punch because of the peaks of pressure produced by the geometrical discontinuity. The resulting worn geometry of the plane after $N_{\max }(=10000)$ wear cycles is given in Fig. 6. These data characterize the uncoated interface, they will allow us to quantify the gain provided by the coating studied in the next section.

\subsection{Coated contact}

The coating was supposed two times harder than the matrix (the plan): $E_{1}=2 * E_{2}=220 G P a$ with a Poisson's ratio $v_{1}=0.3$. 


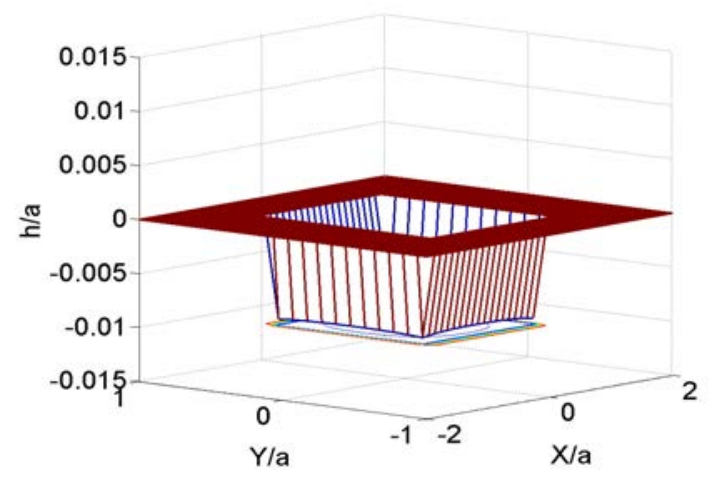

Figure 6: Worn geometry after $N_{M A X}=10000$ cycles

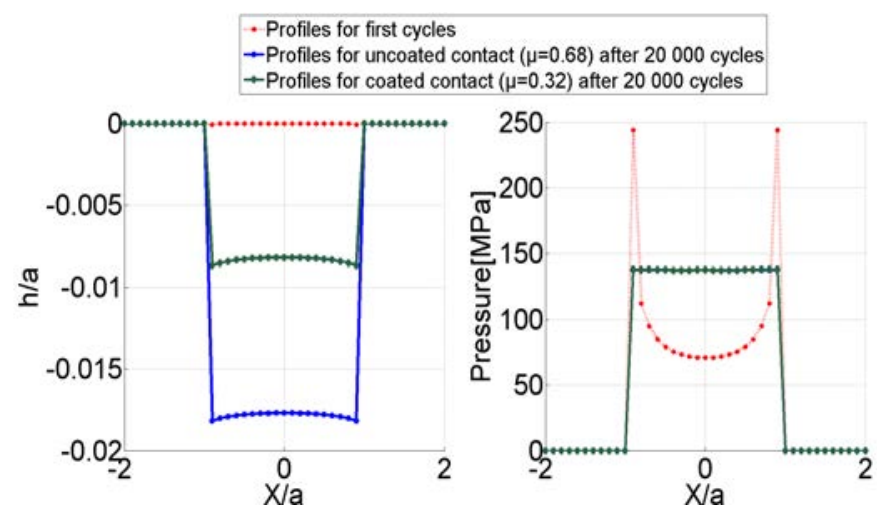

Figure 7: Comparison of coated and uncoated contacts after

$$
N_{M A X}=20000 \text { cycles }
$$

It is characterized by a thickness " $t=400 \mu \mathrm{m} "$. The coefficient of wear is assumed identical. Simulation loading conditions considered are $\mathrm{W}=1150 \mathrm{~N}$ and $\mu=0.32$. Wear is assumed to affect the plan and the punch $(\mathrm{WP}=0.5)$. The simulation is carried out for 20,000 cycles. Comparison between coated and uncoated results are shown in Fig. 7. It is observed that the wear depth for the coated case is reduced by more than half compared to the uncoated case. This result tends to confirm the role of sacrificial coating. The distribution of the shear stress component $\sigma_{x z}$ is plotted in the plane $(\mathrm{x}, \mathrm{z})$ with consideration of wear. It is shown in Fig. 8. The asymmetry is due to the effect of the tangential loading.

\section{CONCLUSION AND PERSPECTIVES}

A semi-analytical contact method has been employed for the simulation of fretting wear. The contact solver is based on the CG method and uses optimized FFT techniques to reduce

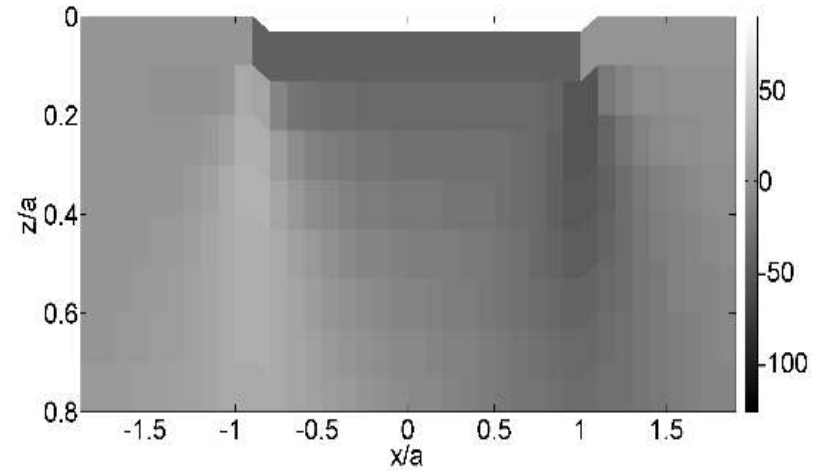

Figure 8: Distribution of the shear stress component $\sigma_{x z}[\mathrm{MPa}]$ in $(\mathrm{x}, \mathrm{z})$ plane

CPU time for contact resolution. A contact model permitting us to simulate coating, based on the equivalent inclusion method in the sense of Eshelby, has been first presented and validated through comparison with Multigrid solutions. The contact solver has been coupled to a wear law proposed by Fouvry and coworkers. The model then enables one to account for surface geometry changes due to wear. Several academic simulations have been performed thanks to the efficiency of the contact solver. Results obtained through this analysis show that wear has a significant impact on the contact pressure distribution and on the geometry of the contacting surfaces, leading to changes even for limited wear. First, the simulations for uncoated contact show that the pressure distribution tends to be flatten, erasing the peaks of pressure at the contact edges. Secondly, for coated surfaces, the numerical method permits to obtain a contact solution for a coating of non-uniform thickness, with is not possible with other analytical techniques such as integral transforms.

\section{ACKNOWLEDGMENT}

This work was supported by the French FUI Project Innolub. The authors gratefully acknowledge all partners of this consortium.

\section{REFERENCES}

[1] Meng, H., and Ludema, K., 1995. "Wear models and predictive equations: their form and content". Wear, 181-183, pp. 443-457.

[2] Fouvry, S., Kapsa, P., and Vincent, L., 1996. "Quantification of fretting damage". Wear, 200, pp. 186-205.

[3] Fridrici, V., Fouvry, S., Kapsa, P., and Perruchaut, P., 2003. "Impact of contact size and geometry on the lifetime of a solid lubricant". Wear, 255, pp. 875-882.

[4] Paulin, C., 2006. "Etude de l'endommagement du contact multicouche aube/disque sous chargement de fretting : im- 
pact des sollicitations variables et de la dimension du contact". PhD thesis, Ecole Centrale de Lyon.

[5] Mary, C., 2009. "Simulation expérimentale de l'usure du contact aube-disque de compresseur sous sollicitations de fretting". PhD thesis, Ecole Centrale de Lyon.

[6] Boucly, V., Nelias, D., and Green, I., 2007. "Modeling of the rolling and sliding contact between two asperities". ASME Journal of Tribology, 129(2), pp. 235-245.

[7] Nelias, D., Antaluca, E., Boucly, V., and Cretu, S., 2007. "A three-dimensional friction model for elastic-plastic contact with tangential loading : Application to dented surfaces". ASME Journal of Tribology, 129(4), pp. 761-771.

[8] Antaluca, E., 2005. “Contribution à l'étude des contacts élasto-plastiques; effet d'un chargement normal et tangentiel". PhD thesis, INSA Lyon.

[9] Gallego, L., 2007. "Fretting et usure des contacts mécaniques : Modélisation numérique". PhD thesis, INSA Lyon.

[10] Gallego, L., Nelias, D., and Jacq, C., 2006. "A comprehensive method to predict wear and to define the optimum geometry of fretting surfaces". ASME Journal of Tribology, 128(3), pp. 476-485.

[11] Gallego, L., and Nelias, D., 2007. "Modeling of fretting wear under gross slip and partial slip conditions". ASME Journal of Tribology, 129(3), pp. 528-535.

[12] Fulleringer, B., and Nelias, D., 2009. "On the tangential displacement of a surface point due to a cuboid of uniform plastic strain in a half-space". Journal of Applied Mechanics, 77(2), p. 021014(7 pages).

[13] Fulleringer, B., 2011. "Semi-analytical modeling of complex mechanical contacts : application to inclusions and swear of coated surfaces". PhD thesis, INSA de Lyon.

[14] Leroux, J., 2013. "Modélisation numerique du contact pour matériaux composites". PhD thesis, INSA de Lyon.

[15] Eshelby, J., 1957. "The determination of the elastic field of an ellipsoidal inclusion and related problems". Proceedings of the Royal Society A: Mathematical,Physical and Engineering Sciences, 241, pp. 376-396.

[16] Chiu, Y., 1977. "On the stress field due to initial strains in a cuboid surrounded by an infinite elastic space". Journal of Applied Mechanics, 44, pp. 587-590.

[17] Wu, L., and Du, S., 1995. "The elastic field caused by a circular cylindrical inclusion: Part i: inside the region $\mathrm{x} 12+\mathrm{x} 22<\mathrm{a} 2,-\infty<\mathrm{x} 3<\infty$, where the circular cylindrical inclusion is expressed by $\mathrm{x} 21+\mathrm{x} 22 \leq \mathrm{a} 2,-\mathrm{h} \leq \mathrm{x} 3 \leq \mathrm{h}$ ". Journal of Applied Mechanics, 62, pp. 579-584.

[18] Wu, L., and Du, S., 1995. "The elastic field caused by a circular cylindrical inclusion: Part ii: inside the region $\mathrm{x} 12+\mathrm{x} 22>\mathrm{a} 2,-\infty<\mathrm{x} 3<\infty$, where the circular cylindrical inclusion is expressed by $\mathrm{x} 21+\mathrm{x} 22 \leq \mathrm{a} 2$, $-\mathrm{h} \leq \mathrm{x} 3 \leq \mathrm{h}$ ". Journal of Applied Mechanics, 62, pp. 585-589.

[19] Leroux, J., Fulleringer, B., and Nelias, D., 2010. “Contact analysis in presence of spherical inhomogeneities within a half-space". International Journal of Solids and Structures, 47 (22-23), pp. 3034-3049.

[20] Boffy, H., Baietto, M.-C., Sainsot, P., and Lubrecht, A., 2012. "An efficient 3d model of heterogeneous materials for elastic contact applications using multigrid methods". Journal of tribology-transactions of the ASME, 134(2).

[21] Kapsa, P., and Cartier, M., 2001. "Usure des Contacts Mécaniques. Manifestations de l'usure". Techniques de lingenieur. Genie mecanique, BD1(BM5067), pp. 1-14.

[22] Archard, J. F., 1953. "Contact and rubbing of flat surfaces". J. Appl. Phys., 24, pp. 981-988.

[23] Fouvry, S., Duó, P., and Perruchaut, P., 2004. "A quantitative approach of ti-6al-4v fretting damage: Friction, wear and crack nucleation". Wear, 257, pp. 916-929.

[24] Paulin, C., Fouvry, S., and Deyber, S., 2005. "Wear kinetics of ti-6al-4v under constant and variable fretting sliding conditions". Wear, 259, pp. 292-299.

[25] Peteghem, B., 2013. "Fretting et fretting-fatigue à haute température d'alliges de titane revêtus". $\mathrm{PhD}$ thesis, Ecole centrale de Lyon. 